\title{
Synergies in the Land Use Sector: What Is the Best Policy Approach When Co-benefits and Trade-offs Are Involved?
}

Martin Lopez

To cite this article: Lopez, M. (2019). Synergies in the Land Use Sector: What Is the Best Policy Approach When Co-benefits and Trade-offs Are Involved?. Central European Economic Journal, 6(53), 53-69.

DOI: 10.2478/ceej-2019-0001.

To link to this article: https://doi.org/10.2478/ceej-2019-0001 


\title{
Central European Economic Journal
}

\author{
Martin Lopez ${ }^{1}$
}

1 Universidad de las Americas Puebla, San Pedro Cholula, MEXICO, corresponding author: martin.lopez@udlap.mx

\section{Synergies in the Land Use Sector: What Is the Best Policy Approach When Co-benefits and Trade-offs Are Involved?}

\begin{abstract}
Mitigation and adaptation are the main strategies to address climate change. Both of them are interrelated instruments and key elements of an integral approach to tackle the phenomenon. This interrelation is particularly strong in the land use sector, an area in which practically any policy has a significant effect on the goals of both strategies. Yet, in practice, mitigation and adaptation are treated as two different instruments. A poor understanding about the interactions between the mentioned strategies remains as a barrier to implement the integrated approach. To contribute to fill-in this knowledge gap, a hypothetical ecologic-economic system simulated under deep uncertainty was used to test environmental and welfare implications of different policy configurations. Taking the unregulated economy as a benchmark, the outcomes of the mentioned interventions were classified as synergies or different forms of trade-offs. Results indicate that measures based on internalization of externalities overcame monetary compensation schemes. Moreover, when externalities were corrected, synergies were more frequent and associated to higher environmental and welfare gains. Furthermore, the policy configuration that exhibited best synergic properties was an intervention integrating mitigation and adaptation measures. This indicates that synergies may be more accessible than previously considered, however, current policy approach and incentives may not be the best tools to trigger them.
\end{abstract}

Keywords: Adaptation, Mitigation, Ecosystem Services, Deforestation, Forest Degradation.

JEL Codes: Q57, Q23, Q24

\section{Introduction}

Mitigation and adaptation are the main strategies to address climate change. Mitigation aims at limiting the degree of the phenomenon by affecting emissions and removals of greenhouse gases from the atmosphere (IPCC 2001). Adaptation, on the other hand, seeks to hamper the side effects of a changing climate by adjusting social and ecological systems to current or expected climate variability (IPCC 2001). It can be said that mitigation addresses the causes of climate change while adaptation focuses on the consequences (Locatelli et al. 2011). However, as some degree of climate change is unavoidable (IPCC 2014), both strategies are important elements of an integral strategy to tackle the phenomenon. Moreover, mitigation and adaptation are interrelated activities: the cost and benefits of mitigation affect the cost and benefits of adaptation and vice versa (Kane and Shogren 2000).

This interrelation is particularly evident in the land use sector, an area in which practically any activity or policy has a significant effect on the goals of both strategies (Locatelli et al. 2015). Yet, in practice, mitigation and adaptation are treated as two different policy instruments (Duguma, Minang, and van Noordwijk 2014), which results in isolated and often uncoordinated efforts to address climate change. One of the main reasons behind this dichotomy is the complexity derived from managing ecologic-economic systems (e.g. landscapes) with multiple goals in mind. 
In other words, as the interactions between mitigation and adaptation are not well understood, tools to assess the integrated outcomes are lacking (IPCC 2014).

Previous research efforts mainly relied in a conceptual approach to analyze the interrelation of climate strategies in the sector mentioned (Locatelli et al., 2011). For instance, in the context of tropical deforestation and forest degradation - the topic analyzed here -, activities with potential to deliver co-benefits (mutual mitigation and adaptation gains) were considered as enhanced policy outcomes or synergies, for short. However, it has also been shown that significant trade-offs between climate strategies might arise when mitigation and adaptation goals are considered (Pramova et al. 2012). For example, when the implementation of a mitigation project restraints the access to forest resources to communities that rely on them (Locatelli et al., 2008).

It is important to highlight that from an economic point of view, the presence of co-benefits does not automatically translate into an enhanced policy outcome. If it is considered that majority of environmental services that contribute to mitigation and adaptation goals are treated as externalities (Barbier, Burgess, and Grainger 2010), economic theory suggests that - unless intervention takes place - outcomes are likely to be sub-optimal (Mas-Colell, Whinston, and Green 1995). Likewise, the presence of a trade-off is not necessarily detrimental for social welfare. As long as the marginal benefits generated from an activity are greater than its costs, performing this activity results in welfare gains (Barbier, Burgess, and Grainger 2010). However, once again, the presence of externalities distorts the private gains and cost from the social ones, pushing the equilibrium away from the optimum. Thus it is evident that in order to address managerial aspects of the integrated implementation of climate strategies, the conceptual approach previously followed must be extended to account for the effects described.

The provision of relevant ecosystem services has been used as a framework to better understand the interactions between mitigation and adaptation (Locatelli et al., 2008). Ecosystem services (ES) are the benefits that societies obtain from functioning ecosystems (Costanza et al. 2017) and they are classified as provisioning, regulating, supporting and cultural (MEA 2003). For mitigation and adaptation purposes, the first two categories are the most relevant ones. Provisioning services are the goods obtained from ecosystems (e.g. agriculture products, wood, charcoal) (MEA 2003). Regulating services are the benefits derived from the regulation of ecological processes (MEA 2003) and they range in spatial scale from global (e.g. carbon storage, biodiversity conservation) to regional (e.g. soil retention, waterflows regulation, micro-climate regulation) (Locatelli et al., 2008). In this regard, mitigation is related to the global dimension of regulating services while adaptation to provisioning and regional regulating services.

It has been showed that contrary to isolated efforts (e.g. only mitigation), the joint implementation of mitigation and adaptation measures restores optimality when co-benefits prevail (Lopez 2016). A situation that takes places, for example, when carbon storage (e.g. the amount of carbon contained in biomass pools) positively correlates with other ES relevant for adaptation. However, it has also been found that carbon storage might have a low correlation with other ES (Locatelli, Imbach, \& Wunder, 2014), which dilutes welfare gains of the integrated approach. Furthermore, as it was mentioned before, the possibility of triggering important trade-offs exists when both strategies are considered. Hence, there is a need to explore implications of the integrated approach in more general situations. It is, when co-benefits but also trade-offs between different ES are explicitly considered as side effects of land reallocation process. The main goal of this paper is to contribute to fill-in this knowledge gap.

One useful framework to analyze the implications of explicitly considering co-benefits and trade-offs between climate strategies is ecosystem services elasticity, which measures how human welfare responds to changes in key environmental stocks (Daw et al. 2016). In this analysis, an adapted version of the concept mentioned was implemented by means of a static optimization model. The model was then used to analyze environmental and welfare implications of different policy configurations in the context of tropical deforestation using exploratory modeling and analysis (EMA) (Kwakkel and Pruyt 2013), a methodology designed to deal with complex and uncertain issues. The mentioned approach helped to identify policy configurations with synergic properties, which were seen as interventions able to simultaneously 
improve mitigation and adaptation indicators with respect to the unregulated situation.

In order to accomplish the goal of the paper, the rest of the manuscript is structured as follows: in the next section the description of the methods is presented. A special emphasis is made on how the concept of ecosystem service elasticity was translated from a conceptual map to an economic optimization problem. Likewise, details about the implementation of EMA are offered. In the third section, the performance of different policy configurations is presented and analyzed with the aim of identifying best policy configurations. The paper finalizes with some concluding remarks. An appendix deals with technical details regarding equilibrium determination (A.1), the specification of regulating measures (A.2) and a brief explanation of forest transition model and the classification of countries according to it (A.3).

\section{Methods}

Based on the classification of ES proposed by Millennium Ecosystem Assessment (MEA 2003) and the concept of ES elasticity (Daw et al. 2016), a conceptual framework that explicitly shows the assumed causal chain between land allocation and welfare for a hypothetical ecologiceconomic system was developed. This framework was translated into a $2 \times 2$ production model (Mas-Colell, Whinston, and Green 1995), which was augmented with the presence of environmental externalities. Following the EMA approach, different policy configurations were simulated under deep uncertainty conditions. The economic model was implemented in $R$ ( $R$ Core Team 2016) using the gEcon package (Klima, Podemski, and Retkiewicz-Wijtiwiak 2016). Data handling and visualization of results were implemented in the same software using the packages dplyr (Wickham et al. 2017), ggplot2 (Wickham 2016) and ggpubr (Kassambara 2017).

The following subsections show in detail the implementation of each of the steps mentioned above.

\subsection{Ecosystem Services Elasticity}

At an aggregated level, the concept of ES suggests a positive relationship between their provision level and human welfare. However, at a lower scale, and especially when one considers their interactions, this relation becomes complex and often indirect (Daw et al. 2016). In the context of tropical deforestation - the main issue analyzed here - there is a trade-off between provisioning services from agriculture and forestry. Both productive activities compete for land, thus - holding everything else constant - the output in one cannot be increased without reducing the output in the other. In fact, agriculture expansion is recognized as the main driver of deforestation at the global level (Hosonuma et al. 2012).

The relation between regulating and provisioning services is even more difficult to observe. However, there seems to be a co-benefit between forestland and agriculture. Empirical evidence supports that forest in the proximity of croplands have a positive effect in yield (Reed et al., 2017), which suggests a positive relation between regional regulating services and agriculture output. In addition, there are interactions among regulating services at different scales. For instance, carbon storage - an important ES for mitigation - exhibits a mixed effect with respect to different regional regulating services. Soil related services (e.g. soil protection or fertility) tend to increase with higher carbon stock (Locatelli et al., 2014). However, water runoff declines with a denser forest (Duncker et al., 2012; Farley, Jobbágy, \& Jackson, 2005; Locatelli et al., 2014). Putting it in another way, carbon storage may be related to both co-benefits and trade-offs.

Taking into consideration the co-benefits and trade-offs related to carbon storage, the impact of deforestation and forest degradation ${ }^{1}$ on social welfare becomes ambiguous. A useful framework to evaluate to what extent these impacts are beneficial for the society is ES elasticity, which measures how human welfare reacts to changes in key environmental stocks by explicitly mapping out the social and ecological links between ecosystems and welfare while considering

1 Forest degradation must be interpreted as a reduction of biomass with respect to a natural forest without involving a land use change. 


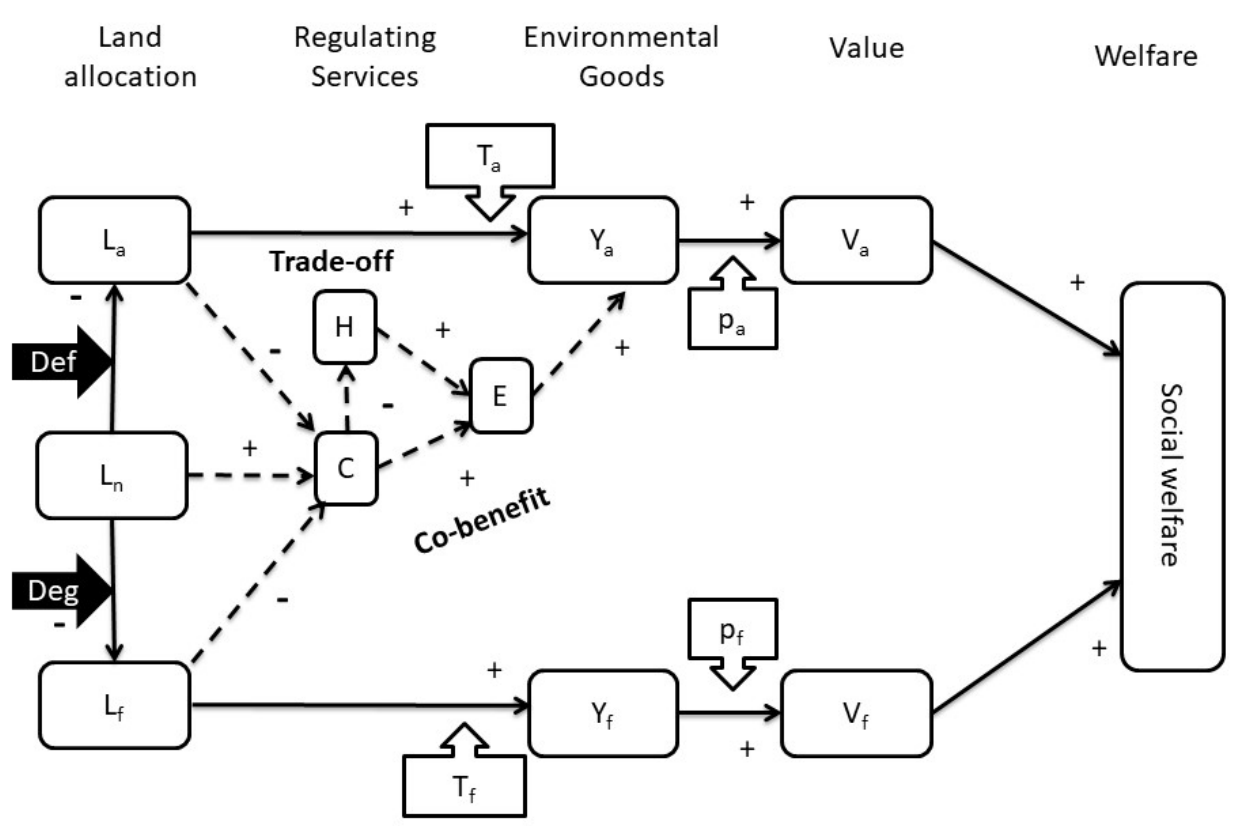

Fig. 1: Conceptual map for tropical deforestation and forest degradation.

Source: author's own elaboration.

specific conditions and context (Daw et al. 2016). For sake of simplicity in the exposition, in the rest of the paper the trade-off among regulating services is referred as a negative relation between carbon storage and hydrological services. However, it should be considered that this relationship is more general and may not necessarily involved to the mentioned services.

\subsection{Conceptual Framework}

The conceptual framework developed for this analysis is displayed in Figure 1. It shows the assumed causal chain from land allocation to social welfare. The figure demonstrates that land can be kept as a natural forest $(L n)$, or reallocated to forestry $(L f)$, or to agriculture $(L a)$. The sign in the link that connects these variables represents their relation. It is negative because increasing land allocation in one productive use is made at the expense of the natural forest, a situation that is representative of what occurs in the tropical region (Hosonuma et al. 2012). The reallocation process also determines the main impacts studied here: deforestation and degradation.

Land allocation determines the output of environmental goods $(Y a, Y f)$ and carbon stock level (C). In the case of output, land and labor $(T)$ are combined to perform the production process. Naturally, a higher allocation of land to any productive activity leads to a higher output, which explains the positive sign between these variables. It is additionally assumed that output prices $(p a, p f)$ determine the value of output, which is positively related to social welfare.

The reallocation of land, however, has a negative impact on carbon stock. Two main consequences follow from this: firstly, hydrological services $(H)$ increase and, secondly, the state of the environment $(E)$ decreases. Notice that the first effect constitutes a trade-off while the second is a co-benefit. As a consequence, the overall impact of land reallocation on output and ultimately on welfare is ambiguous. The dotted lines in this section of the diagram indicate that these relations are considered as externalities when the economy is unregulated.

\subsection{Model}

Based on the conceptual framework presented in the previous subsection, a $2 \times 2$ production model augmented with an externality was developed with the purpose of deriving equilibrium allocation of resources and provision level of the ES under consideration. The model derives the equilibrium allocation by solving the optimization problem of the representative firms in the agriculture and forestry subsectors. As it was indicated 
before, the provision level of ES is determined by land allocation and it has an impact on agriculture output. In what follows, the mathematical representation of these processes is shown. The appendix shows further details regarding equilibrium determination and regulating measures.

To begin with, the representative firm in each subsector (agriculture and forestry) is assumed to be competitive and its goal is to maximize profits subject to a technological constraint. In addition, the profit function considers the policy followed, which takes the form of a Pigouvian tax/subsidy on land. In mathematical terms, the problem of the firm is:

$\max _{L_{j}, T_{j}} \Pi_{j}=p_{j} Y_{j}-w T_{j}-\left(r+t_{j}\right) L_{j}$

s.t. $Y_{j}=F\left(T_{j}, L_{j}\right)$

Where: $\Pi$ are profits; $Y$ is the output level; $T$ is labor used in the subsector; $L$ is land allocated to that subsector; $p$ is the output price; $w$ is the wage rate; $r$ is the opportunity cost of land; $t$ is the tax/subsidy on land in a subsector (see appendix); and the subscript $j$ represents the subsector (a: agriculture, $f$ : forestry).

A small open economy setting is followed, which implies that output prices are exogenously determined. Thus, the overall value of the production of the given economy is:

$$
\mathrm{GDP}=p_{a} F(E) Y_{a}+p_{f} Y_{f}+r L_{n}
$$

Where: $F(E)$ is a concave function in terms of the state of the environment $(E)$, defined later in equation (5); and the subscript $n$ represents natural forest standing.

In this analysis the GDP is used as the social welfare measure and changes in this variable are interpreted as an adaptation indicator as a proxy to regional welfare. In addition, the last term in equation (2) represents a compensation scheme dependent on policy configuration. In the unregulated setting, this term is zero as no land is left as a natural forest.

At this point, it is important to clarify that the use of GDP as a measure of welfare is subject of debate and alternative measures have been proposed to better assess this dimension of sustainable development (Giannetti et al. 2015; Kubiszewski et al. 2013) . However, as the model presented here is formulated, the GDP formulation simply captures the behavior of output value, leaving aside any further complexity that in reality might take place. This implies that a weak sustainability approach is followed, or in other words, a non-declining consumption is considered the indicator of sustainability (Ang and Van Passel 2012; Davies 2018).

Land allocation directly affects carbon stock through deforestation and degradation. These impacts affect $C$ as follows:

$\mathrm{C}=C_{\max }-\bar{C} L_{a}-d L_{f}$

Where:

$\mathrm{C}$ is the carbon stock contained in biomass; Cmax is the maximum level of carbon stock; $\bar{C}$ is the average carbon storage per unit of land; $d$ is the degradation parameter.

The previous equation can be interpreted as follows: if no production process is performed, carbon stock is at its maximum capacity (the first term on the right hand side of equation (3)). However, if land is reallocated to agriculture, $C$ is affected by deforestation. In particular, every unit of forestland lost implies a reduction equivalent to the average carbon storage (second term in the right hand side of the equation). Similarly, when land is allocated to forestry, $C$ is reduced by degradation. In this case, biomass extraction reduces the carbon stock in a fixed proportion (third term on the right hand side).

Changes in the carbon stock affect the provision level hydrological services and the state of the environment. More specifically, it is assumed that the provision of $H$ negatively and non-linearly relates to $C$. To capture this relation, a Hill function was followed:

$\mathrm{H}(\mathrm{C})=\frac{1}{1+(C / k)^{n}}$

Where: $H$ is the provision level of hydrological services; $k$ is a parameter that determines the inflection on the horizontal axis; $n$ is a parameter that determines the steepness around the inflection.

This formulation implies that when carbon stock is reduced, either by deforestation or degradation, the provision of hydrological services increases (e.g. due to lower evapotranspiration). 
The state of the environment is specified by a normalized CES function (Barro and Sala-i-Martin 2004) that depends on $C$ and $H$ as follows:

$\mathrm{E}(\mathrm{C}, \mathrm{H}(\mathrm{C}))=\left[s\left(\frac{C}{C_{\max }}\right)^{\psi}+(1-s)\left(\frac{H(C)}{H\left(C_{\max }\right)}\right)^{\psi}\right]^{1 / \psi}$

Where: $H$ is the provision level of hydrological services; $s \in[0,1]$ is the carbon share parameter; $\psi$ is $\frac{\sigma-1}{\sigma} ; \sigma$ is the elasticity of substitution between $\mathrm{C}$ and $\mathrm{H}$.

This formulation captures the key idea that ES at aggregated level increase welfare but, at a lower level, their effect on the indicator mentioned is ambiguous and indirect. For example, a decrease in $C$ means a lower value in the first term of the equation but a higher one in the second term. The parameters of equations (4) and (5) determine the net effect of the change mentioned.

Figure 2 illustrates the effect of land use change on the state of the environment at aggregated level, which results from the combination of equations (4), (5) and different sets of parameters. It is precisely this relation, the one treated under deep uncertainty conditions, as it will be detailed later. The dotted line shows the unregulated situation: it is inaccurately perceived that land use change has no effect on the state of the environment. However, the reduction of the carbon stock through land reallocation has an initial ambiguous effect on the state of the environment. For instance, a combination of parameters might immediately deteriorate it, as the black line shows. Other combination of parameters might exhibit an initial smoother response, as indicated by the blue curve. There is even the possibility of initially observing a relatively neutral response in the state of the environment, as the red line illustrates. Excessive land use change, nevertheless, leads to a deterioration of the environment and lower productivity in all cases. Situations like the one exemplified in by the gray curve are considered unrealistic, as excessive land use change would lead to an improvement in the state of the environment.

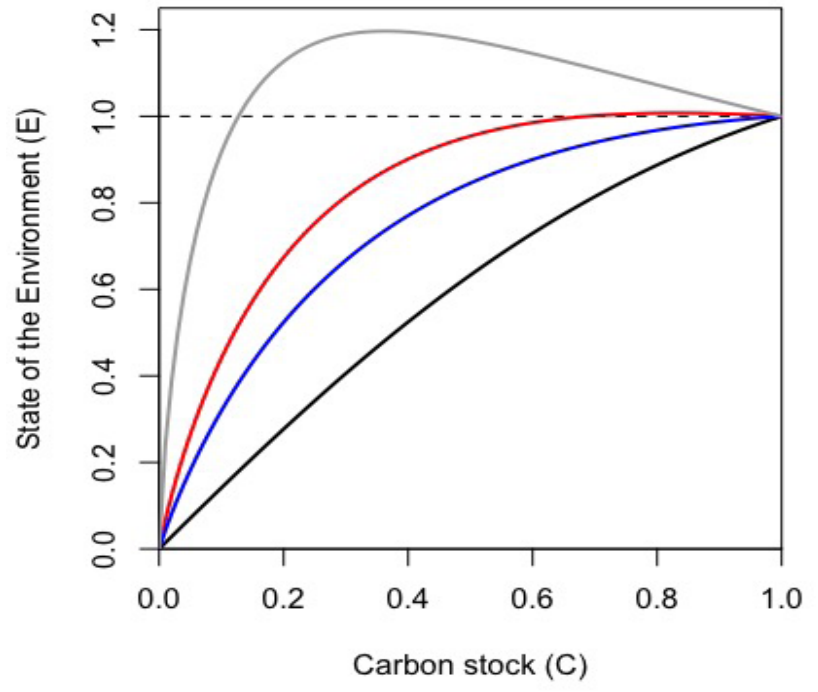

Fig. 2: Effect of land use change on the overall provision of regulating ES given different parameters specification.

Source: author's own elaboration. Notice that equation 5 is defined in terms of $\mathrm{C}$ and $\mathrm{H}$, however, $\mathrm{H}$ is a function of $\mathrm{C}$. Thus, the resulting curve can be plotted using only in terms of $C$. Parameter specification is as follows:

Black curve: $\mathrm{s}=0.7, \sigma=0.5$

Blue curve: $\mathrm{s}=0.4, \sigma=0.7$

Red curve: $\mathrm{s}=0.5, \sigma=0.7$

Gray curve: $\mathrm{s}=0.25, \sigma=0.75$

\subsection{Implementation of Exploratory Modeling and Analysis}

The EMA approach is a research methodology designed to analyze complex systems under deep uncertainty conditions. These are situations where it is reasonable to incompletely enumerate multiple possibilities without being able to rank how likely these are judged to be. In the context of EMA, a single model run is considered an experiment and it reveals how the system would behave if various guesses were correct. By conducting multiple experiments, it is possible to explore the implications of those guesses (Kwakkel and Pruyt 2013).

In this exercise, the model shown in the previous section was simulated using different policy configurations considering deep uncertainty in parameters specification. Specific details about model quantification and simulation settings are shown in the next subsections. 


\subsubsection{Model Calibration}

In order to derive a numerical solution of the model presented in the previous section a Cobb-Douglas production function exhibiting constant returns to scale was used for both subsectors. The selected parameters, presented in Table 1, show that the assumption of relative factor intensities was followed. In particular, it is assumed that forestry sector is relatively intensive in land while agriculture sector is relatively intensive in labor. Additionally, to reflect that deforestation is driven by agriculture expansion, the price of agriculture output was set 35 percent higher than forestry output. Parameters selected replicate average land allocation in tropical countries at the late transition phase, which is around 21 percent for degraded forest, natural forest is nearly zero in the phase mentioned (Hosonuma et al. 2012).

The externality associated to the state of the environment - the function $F(E)$ (see equation (2)) was defined in the following form: $E^{r}$, which follows the assumption of marginal decreasing benefits of forests (Barbier, Burgess, and Grainger 2010). Given the uncertainty associated to this process, the parameter $\gamma$ was selected to roughly replicate observed forest cover along the different phases of the forest transition process. This means that land allocated to forestry is around 70 percent (e.g. at the early transition phase) or less (e.g. at later stages) of total land endowment (Hosonuma et al. 2012). Thus, the parameter gamma was selected to avoid unrealistic allocations at equilibrium.

Resource endowments and maximum carbon storage were normalized with the purpose of simplifying the interpretation of results. In this way, allocation of resources is measured in relative terms and changes in carbon stock are reported as the fraction remaining with respect to its maximum level. The provision of hydrological services (see equation (4)) was assumed to respond smoothly to initial changes in carbon stock. Notice that parameters described so far were fixed during simulations.

Parameters of equation (5) were randomly specified with the purpose of capturing the context specific nature of adaptation. In other words, it is considered that the same system structure applies in all regions (see Figure 1). However, parameters defining the relationships in particular those capturing the externality associated from forest ecosystems to agriculture (see doted lines in Figure 1) -, differ from region to region. It must be considered that the functional form of the equation mentioned along with complementarity of regulating services restrain the plausible range of values that the relevant parameters might take. The carbon share parameter, for instance, is naturally defined for range of values between zero and one. It is additionally assumed that balanced profiles, where both ES are important to define the state of the environment (e.g. the parameter $s$ takes values around 0.5 ), are more commonly observed. Therefore, the variation of this parameter followed a normal distribution as specified in Table 1.

A similar reasoning allowed to specify the range of values for the elasticity of substitution. More precisely, given equation (4) and the assumed variation of the parameter $s$, plausible shapes for $E$ arise for relatively low values for the elasticity of substitution. In this case, however, there are no reasons to assume that the elasticity centers around a particular value. Thus, a uniform distribution was followed.

The variation in the degradation parameter was defined according to values reported in the literature. The main drivers of degradation at the world level are timber extraction and wood fuel collection (Hosonuma et al. 2012). Based on reports for Brazil, fuel wood collection represents extraction level between 19\% and $35 \%$ of the standing biomass (Specht et al. 2015). Likewise, depending on its intensity, timber extraction reduces standing biomass between $20 \%$ and $48 \%$ with respect to natural forest (Gerwing 2002). The model developed here does not distinguish between the different sources of degradation. Hence, to capture the full range of values reported, the variation of this parameter was specified following a uniform distribution ranging from 0.1 to 0.5 .

\subsubsection{Policy Configurations}

Five different policy experiments were performed. The purpose of these experiments was to identify policy approaches consistent with the definition of synergy. A general overview of the configuration of these scenarios is shown in Table 2.

In the unregulated scenario no corrective action takes place and no fraction for natural forest standing 
Tab. 1: Parameters of the model.

\begin{tabular}{|c|c|c|c|}
\hline \multicolumn{4}{|c|}{ Fixed parameters } \\
\hline Parameter & Value & Description & Source \\
\hline a & 0.3 & $\begin{array}{l}\text { Exponent agriculture land in production } \\
\text { function }\end{array}$ & \multirow[t]{4}{*}{$\begin{array}{l}\text { Jointly determined to replicate late transition } \\
\text { phase as reported in Hosonuma et al. } 2012\end{array}$} \\
\hline$\beta$ & 0.7 & $\begin{array}{l}\text { Exponent agriculture land in production } \\
\text { function }\end{array}$ & \\
\hline$p_{a}$ & 1.3 & Output price agriculture & \\
\hline$p_{f}$ & 1 & Output price forestry & \\
\hline$\gamma$ & 0.25 & $\begin{array}{l}\text { Exponent of state the state of the } \\
\text { environment in externality function }\end{array}$ & $\begin{array}{l}\text { Value selected to replicate forest cover along the } \\
\text { different phases of forest transition as reported in } \\
\text { Hosonuma et al. } 2012\end{array}$ \\
\hline$C_{\max }$ & 1 & Maximum carbon stock (Normalized) & \multirow{3}{*}{$\begin{array}{l}\text { The values could not be derived from the lite- } \\
\text { rature directly. Nevertheless they are consistent } \\
\text { with what can be found there }\end{array}$} \\
\hline$\overline{\mathrm{L}}$ & 1 & Land endowment (Normalized) & \\
\hline$\overline{\mathrm{T}}$ & 1 & Labor endowment (Normalized) & \\
\hline k & 0.25 & Inflection point of Hill function & $\begin{array}{l}\text { Assumption consistent with mathematical } \\
\text { formulation }\end{array}$ \\
\hline $\mathrm{n}$ & 1 & Steepness Hill functions & $\begin{array}{l}\text { Assumption consistent with mathematical } \\
\text { formulation }\end{array}$ \\
\hline \multicolumn{4}{|c|}{ Random Parameters } \\
\hline s & $\mathrm{N}(0.5,0.083)$ & Carbon share & $\begin{array}{l}\text { Assumption consistent with mathematical } \\
\text { formulation* }\end{array}$ \\
\hline$\sigma$ & $U(0.1-0.85)$ & Elasticity of substitution & $\begin{array}{l}\text { Assumption consistent with mathematical } \\
\text { formulation }\end{array}$ \\
\hline$d$ & $\mathrm{U}(0.1-0.5)$ & Degradation & Specht et al 2015 and Gerwing 2002 \\
\hline
\end{tabular}

Source: author's own elaboration based on indicated sources.

* Implausible shapes for equation 2.5 are seen if parameters are outside the specified ranges.

is required. As its name indicates, this scenario aims to replicate the situation in which no policy is implemented. The main consequence of simulating this configuration is that all land is allocated to one of the productive uses. In the reserve scenario the only change with respect to the unregulated economy is that a fraction of land is compulsorily left as a natural forest standing. This situation would take place, for instance, when a specific area is declared as a natural reserve. A similar setting is followed under the compensation scenario. However, in this configuration the fraction left as natural forest is compensated. This is achieved by adding opportunity cost of land to GDP (see equation (2)). This configuration would take place when a mitigation project, such as REDD+ (Reduction of Emissions from Deforestation and forest Degradation), is implemented. In such a case, an outside subsidy (e.g. from international community) would be paid to landowners joining to the program. The main purpose of including these configurations is to evaluate the performance of current policy approaches and compare it with the alternative ones analyzed here, based on internalization of externalities.

The mitigation scenario $(M)$ assumes that, in addition to a quota for natural forest, a corrective measure (tax on land use) is implemented in agriculture sector based on changes in the state of the environment due to a carbon 
Tab. 2: Policy configurations.

\begin{tabular}{|c|c|c|c|c|}
\hline Policy/configuration & $\mathrm{L}_{\mathrm{n}}$ quota* $(\%)$ & Compensation $^{+}$ & Agr & For \\
\hline Unregulated & 0 & No & - & - \\
\hline Reserve & 7 & No & - & - \\
\hline Compensation & 7 & Yes & - & - \\
\hline Mitigation & 7 & No & Tax on C & - \\
\hline Adaptation & 7 & No & - & Subcidy on $\mathrm{H}$ \\
\hline Policy integration & 7 & No & Tax on C & Subcidy on $\mathrm{H}$ \\
\hline
\end{tabular}

Source: Author's own elaboration.

Notes:

* Percentage of total land endowment.

+ When compensation mechanism is active (yes), the amount of land kept as natural forest $(L n)$ is compensated based on its opportunity cost $(r)$, otherwise compensation is zero, see equation (2) and appendix A.1 for details.

A tax implies that $t>0$, while a subsidy means that $t<0$. Otherwise, $t=0$. See equation (1) and appendix A.2. for details.

loss. The adaptation scenario $(A)$ considers the same land quota as before, however, a corrective measure is implemented in the forestry sector (subsidy on land use) based on its contribution to the state of the environment due to hydrological services. The last scenario analyzed - policy integration (PI) - keeps the same quota and combines the previously described policies ( $M$ and $A$ ). In other words, it implements corrective measures in both subsectors. This implies a tax on land use in agriculture and a subsidy in forestry.

To perform EMA analysis, one thousand random numbers for each parameter specified in Table 1 were generated. These numbers were used to determine the equilibrium according to policy configuration and parameterization of the model. Each experiment was classified as a synergy or a form of trade off. In other words, carbon storage (mitigation indicator) and resulting GDP (adaptation indicator) in the unregulated economy were used as a benchmark to determine the impact of the specific policy design: a synergy implies that both criteria are improved with respect to the unregulated economy. On the contrary, a tradeoff indicates that the policy improves one criterion by worsening the other. Two categories of trade-offs are possible: mitigation trade-off (MT) and adaptation trade-off (AT). The former indicates that a gain in carbon implies a reduction in GDP while the latter indicates that a gain in GDP requires further carbon losses. Lastly, a fourth category was defined as disjunction, which indicates that policy intervention deteriorates both indicators with respect to the unregulated situation.

\section{Results}

For each policy scenario considered, one thousand (reproducible) simulations were performed according to the specifications described in the previous section. Unsuccessful (equilibrium was not found) and unrealistic ( $E>1$ at equilibrium, indicating that excessive deforestation improves the state of the environment) outcomes were removed. This filtering process left 4991 out of the five thousand experiments. After that, the classification frequency observed by each policy scenario and quantitative synergy properties of the different policy scenarios were further analyzed.

\subsection{Classification Frequency}

Figure 3 displays the classification of outcomes of each policy scenario analyzed. As it can be seen from the figure, the scenarios based on current policy approaches (reserve and compensation) perform poorly compared to the scenarios implementing alternative policy schemes, based on the internalization of externalities (adaptation, mitigation and policy integration). For example, a disjunction was observed in $22 \%$ of the times in the case of reserve and compensation scenarios. Likewise, 
a mitigation trade off was observed $74 \%$ of the times in the case of reserve and $16 \%$ of the times in the case of compensation scenario. And a synergy was observed 4 and $62 \%$ of the times respectively. These last numbers show that the main effect of a compensation scheme is to switch some of the instances from a mitigation trade off to a synergy, which reflects the relevance of the mechanism mentioned in the design of current environmental policy in the land use sector.

A drastically different behavior was observed when alternative policies were implemented. As the figure shows, only a small fraction of instances corresponded to disjunction $(2 \%)$ or mitigation trade off $(16 \%)$ when adaptation policy was implemented. Moreover, synergies were observed in all cases under mitigation and policy integration scenarios.

\subsection{Synergies Properties}

It is worth noticing that synergies associated to each policy have varying quantitative properties, which were not possible to distinguish in the qualitative analysis presented previously. In other words, it was not possible to elucidate whether improvements in mitigation and adaptation indicators were substantially higher in a specific policy intervention. Figure 4 shows a notched box-plot of synergic outcomes in environmental ( $\mathrm{C}$ in left panel) and welfare terms (GDP in right panel), no overlapping notches indicate an statistically different median in different groups (Wickham 2016). As the figure reveals, the overall performance of current policy approaches is weak compared to alternative ones in both indicators. The median equilibrium carbon stock is considerably lower in the reserve and compensation scenario ( 0.13 and 0.15 respectively) than in the alternative policies (A:0.28, M:0.38, PI:0.42). It follows that forestland conservation tended to be higher in the alternative policies.

A similar behavior is observed in GDP with the difference that this indicator shows a higher variability in reserve and compensation scenarios, as it is shown by the width of the boxes and the outliers. This reflects that only under very specific conditions current policy approaches are comparable to alternative ones in adaptation terms.

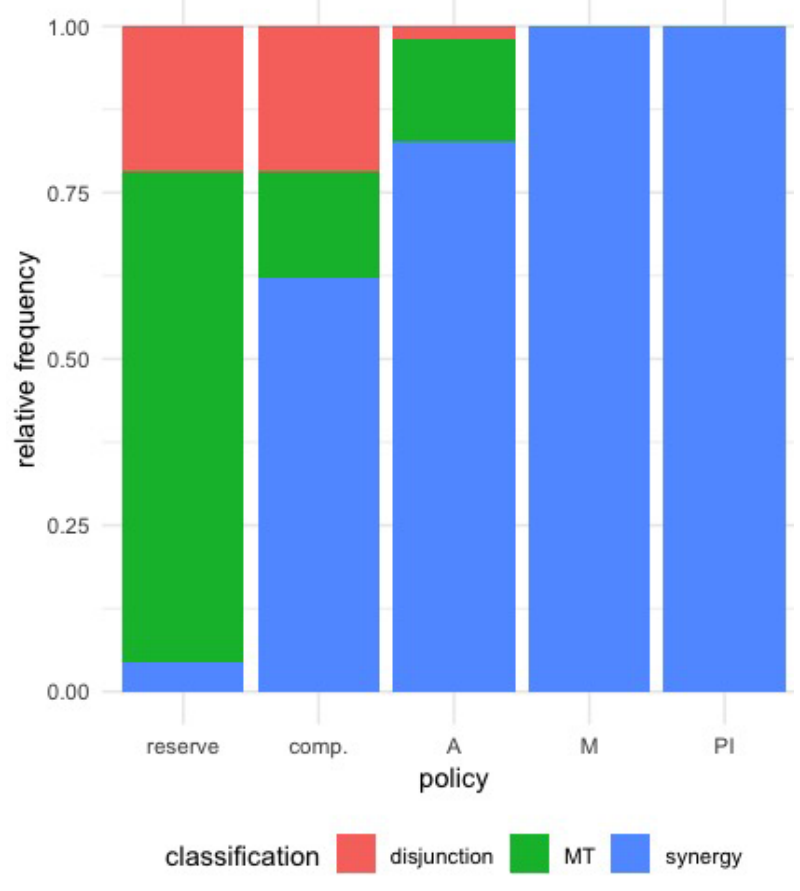

Fig. 3: Classification frequency of different policy scenarios. Source: author's own elaboration.

The results obtained in reserve and compensation scenarios can be anticipated using the Rybczynski theorem (Mas-Colell, Whinston, and Green 1995). Specifically, the net effect of decreasing the endowment of land is an increase in the amount of this factor allocated to agriculture, the relatively less land intensive sector. The magnitude of this effect is fully explained by technologies and output prices. As the parameters that defined those relations remained fixed, the resulting allocation of land was the same for all experiments in these configurations. It follows that synergies are determined by extraction level in forestry sector (degradation parameter) and compensation level (see equation 2 , in particular the third element in the right hand side). In the case in which these effects overcome GDP loss due to land endowment reduction and extraction in forestry sector allows a net carbon gain, a synergy is realized. However, as land allocation remains fixed, only relatively weak synergies were expected under these schemes.

The mechanism described so far also takes place in the other three configurations. However, it is complemented by the internalization of the relevant externality. Depending on policy configuration, the 

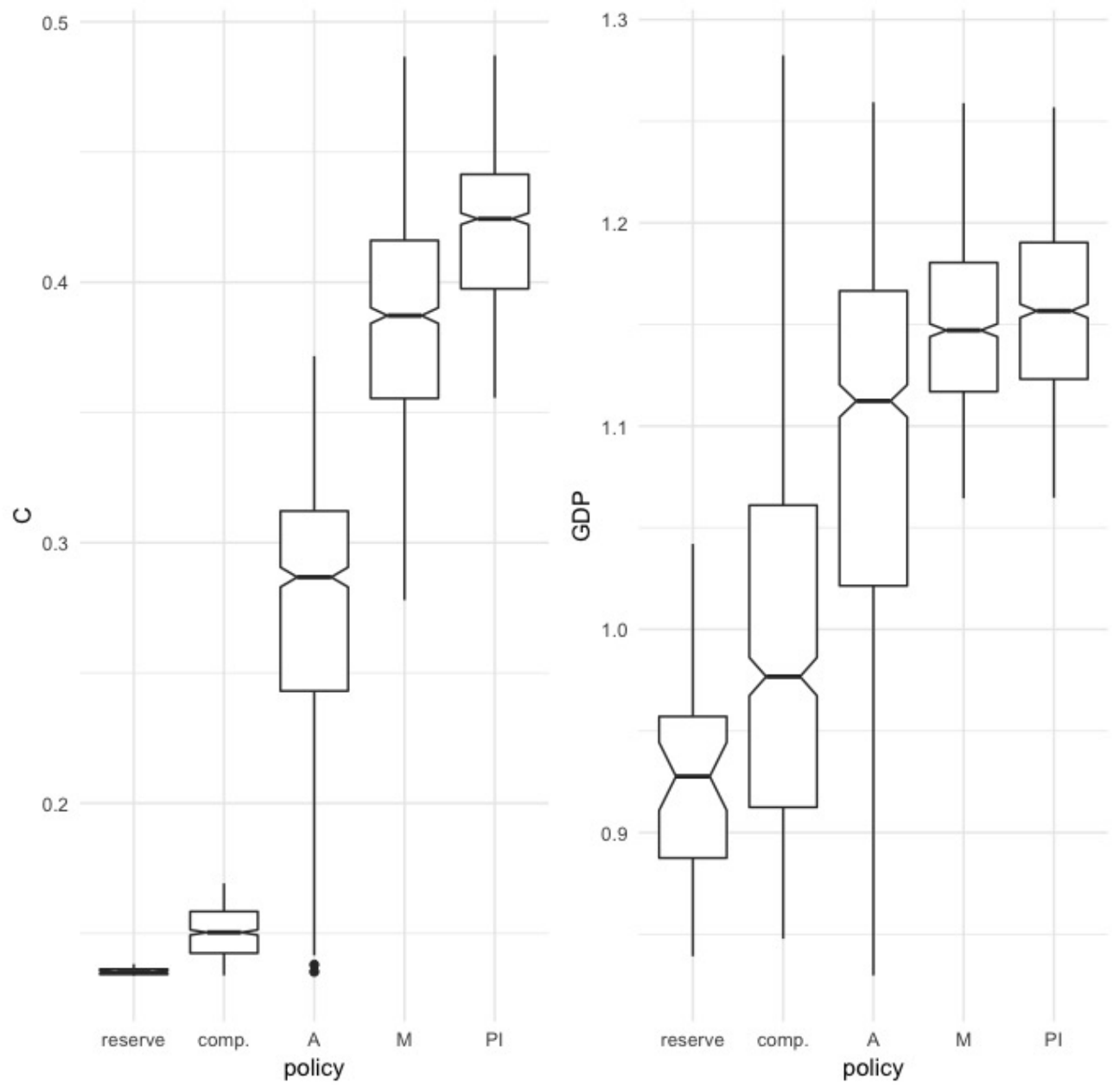

Fig. 4: Environmental (C) and welfare indicators (GDP) of synergic outcomes by policy Source: author's own elaboration.

opportunity cost of land is modified to account for the effect that the economic subsector has on a particular environmental service. As a consequence, the allocation of factors is determined not only by the parameters mentioned before but also by the impact that land reallocation has on the provision of ES. At this point it is convenient to recall that ES determining the state of the environment (see equation (5)) were treated under deep uncertainty conditions. Thus, variability was involved and only general patterns could have been identified.

Figure 5 summarizes the results obtained for the alternative policy scenarios. The scatterplot plot in this figure shows two distinctive patters: mitigation and PI tend to group on a cloud located in the top right corner while adaptation exhibited a positively sloped shape. As the carbon density plot reveals (top panel), the main characteristics of the clouds formed by $\mathrm{M}$ and PI is that, in general, these configurations conserve a higher fraction of carbon compared to adaptation. In addition, these configurations delivered a higher GDP (see the right panel). The figure explains why synergies are stronger in M and PI scenarios. However, PI exhibited an even better performance, as carbon storage tended to be higher under this configuration without sacrificing GDP.

\section{Conclusions}

In this paper the joint implementation of mitigation and adaptation measures was analyzed assuming co-benefits and trade-offs among different provisioning 

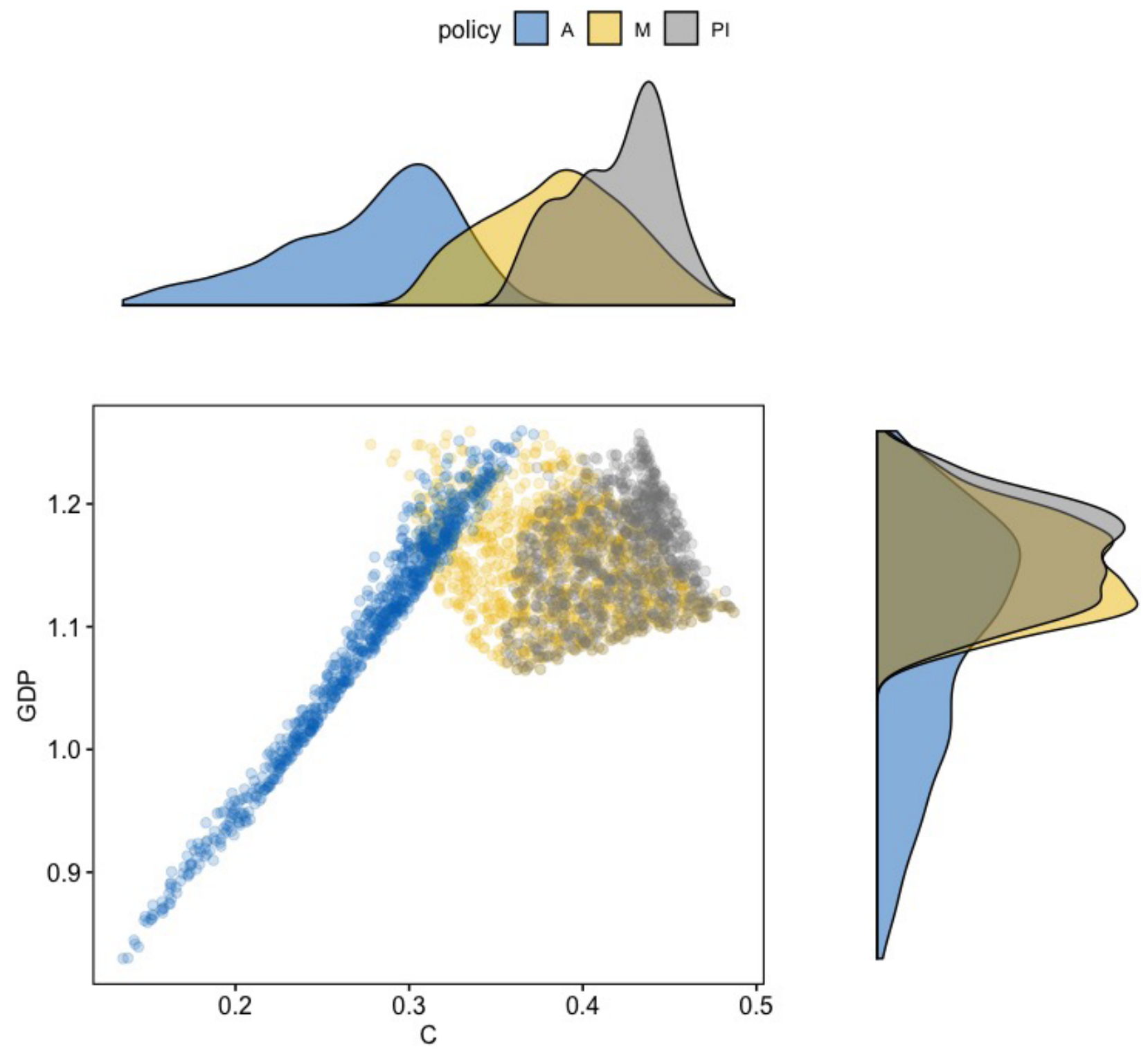

Fig. 5: Environmental and welfare indicators of alternative policy scenarios.

Source: author's own elaboration.

and regulating ecosystem services. Concretely, a hypothetical ecologic-economic system in which deforestation and degradation of forest directly impacted output level of relevant economic activities was constructed. It was additionally considered that land use change indirectly affected output through the provision of competing regulating ecosystem services. Due to current knowledge gaps, this last relation was treated under deep uncertainty.

Different policy scenarios grouped in two main categories, current mechanisms and internalization of externalities, were tested. The simulated outcome suggest that the latter approach overcame the former in economic and environmental terms. Putting it differently, a higher carbon stock and GDP were associated to the second group of policy mechanisms. Moreover, policy integration - a mechanism combining mitigation and adaptation measures in the land use sector as a whole-, exhibited the best performance among the interventions in the second group.

The mentioned results indicate that synergies may be more common and accessible than previously 
Tab. 3: Variables calculated for the numerical solution of the model and their use.

\begin{tabular}{|c|c|c|}
\hline \multicolumn{3}{|c|}{ Economic subsectors } \\
\hline Variable & Description & Use \\
\hline$\Pi_{j}$ & Profit & $\begin{array}{l}\text { Not reported but known to } \\
\text { be zero }\end{array}$ \\
\hline$Y_{j}$ & Production & Calculate GDP \\
\hline $\mathrm{L}_{\mathrm{j}}$ & Land use & Model calibration \\
\hline $\mathrm{T}_{\mathrm{j}}$ & Labor use & Not reported \\
\hline$\lambda_{j}$ & Shadow price & Not reported \\
\hline \multicolumn{3}{|c|}{ Factors Markets } \\
\hline w & Wage rate & Not reported \\
\hline$r$ & $\begin{array}{l}\text { Opportunity } \\
\text { cost of land }\end{array}$ & $\begin{array}{l}\text { Calculate GDP (depending } \\
\text { on policy configuration) }\end{array}$ \\
\hline \multicolumn{3}{|c|}{ Ecologic sector } \\
\hline $\mathrm{C}$ & Carbon stock & Mitigation indicator \\
\hline $\mathrm{H}$ & $\begin{array}{l}\text { Hydrological } \\
\text { services }\end{array}$ & $\begin{array}{l}\text { Indirectly contained in GDP } \\
\text { calculation }\end{array}$ \\
\hline $\mathrm{E}$ & $\begin{array}{l}\text { State of the } \\
\text { environment }\end{array}$ & Calculate GDP \\
\hline
\end{tabular}

Source: author's own elaboration.

Tab. 4: Average forest cover in 2010 per phase of forest transition process.

\begin{tabular}{lll}
\hline Phase & $\begin{array}{l}\text { Number of } \\
\text { countries }\end{array}$ & $\begin{array}{l}\text { Average forest } \\
\text { cover (\%) }\end{array}$ \\
\hline Pre transition & 13 & 69.9 \\
\hline Early transition & 39 & 46.6 \\
\hline Late transition & 33 & 21.3 \\
Post transition & 15 & 27.3 \\
\hline
\end{tabular}

Source: author's own elaboration based on World Bank data.

considered, however, current dichotomy approach (e.g. adaptation and mitigation) and mechanism (e.g. compensation) may not be the best tools to trigger them. Furthermore, the importance of conceiving the land use sector as an entity rather than as a set of isolated components (e.g. agriculture and forestry) was highlighted.

\section{References}

[1] IPCC. 2001. Climate Change 2001, Synthesis Report. Cambridge University Press.

[2] - - - 2014. Climate Change 2014: Synthesis Report. Contribution of Working Groups I, II and III to

[3] Kassambara, A. 2017. Ggpubr: 'ggplot2' Based Publication Ready Plots. (version 0.1.5). R.

[4] Mas-Colell, A., M.D. Whinston, and J.R. Green. 1995. Microeconomic Theory. Oxford Student Edition. Oxford University Press. https://books. google.pl/books?id=KGtegVXqD8wC.

[5] MEA. 2003. Ecosystems and Human Well-Being: A Framework for Assessment. Island Press.

[6] World Bank. 2018. 'Forest Area (\% of Land Area) | Data'. 2018. https://data.worldbank.org/ indicator/AG.LND.FRST.ZS?view=chart.

[7] Ang, Frederic, and Steven Van Passel. 2012. "Beyond the Environmentalist's Paradox and the Debate on Weak versus Strong Sustainability." BioScience 62 (3): 251-59.

[8] Barbier, Edward B, Joanne C Burgess, and Alan Grainger. 2010. "The Forest Transition: Towards a More Comprehensive Theoretical Framework." Land Use Policy 27 (2): 98-107.

[9] Barro, R, and Xavier Sala-i-Martin. 2004. “Economic Growth, Chapter 2." MIT Press, Cambridge.

[10] Costanza, Robert, Rudolf de Groot, Leon Braat, Ida Kubiszewski, Lorenzo Fioramonti, Paul Sutton, Steve Farber, and Monica Grasso. 2017. “Twenty Years of Ecosystem Services: How Far Have We Come and How Far Do We Still Need to Go?" Ecosystem Services 28: 1-16.

[11] Davies, George Randal. 2013. “Appraising Weak and Strong Sustainability: Searching for a Middle Ground." Consilience, no. 10: 111-24.

[12] Daw, Tim, Christina Hicks, Katrina Brown, Tomas Chaigneau, Fraser Januchowski-Hartley, William Cheung, Sérgio Rosendo, Beatrice Crona, Sarah Coulthard, and Chris Sandbrook. 2016. "Elasticity in Ecosystem Services: Exploring the Variable Relationship between Ecosystems and Human Well-Being." Ecology and Society 21 (2): 11.

[13] Duguma, Lalisa A, Peter A Minang, and Meine van Noordwijk. 2014. "Climate Change Mitigation 
and Adaptation in the Land Use Sector: From Complementarity to Synergy." Environmental Management 54 (3): 420-32.

[14] Duncker, Philipp S, Karsten Raulund-Rasmussen, Per Gundersen, Klaus Katzensteiner, Johnny De Jong, Hans Peter Ravn, Mike Smith, Otto Eckmüllner, and Heinrich Spiecker. 2012. "How Forest Management Affects Ecosystem Services, Including Timber Production and Economic Return: Synergies and Trade-Offs." Ecology \& Society 17 (4).

[15] Farley, Kathleen A, Esteban G Jobbágy, and Robert B Jackson. 2005. "Effects of Afforestation on Water Yield: A Global Synthesis with Implications for Policy." Global Change Biology 11 (10): 1565-76.

[16] Gerwing, Jeffrey J. 2002. “Degradation of Forests through Logging and Fire in the Eastern Brazilian Amazon." Forest Ecology and Management 157 (1-3): 131-41.

[17] Giannetti, B F, Feni Agostinho, CMVB Almeida, and Donald Huisingh. 2015. "A Review of Limitations of GDP and Alternative Indices to Monitor Human Wellbeing and to Manage Eco-System Functionality." Journal of Cleaner Production 87: 11-25.

[18] Hosonuma, Noriko, Martin Herold, Veronique De Sy, Ruth S De Fries, Maria Brockhaus, Louis Verchot, Arild Angelsen, and Erika Romijn. 2012. "An Assessment of Deforestation and Forest Degradation Drivers in Developing Countries." Environmental Research Letters 7 (4): 44009.

[19] Kane, Sally, and Jason F Shogren. 2000. "Linking Adaptation and Mitigation in Climate Change Policy." In Societal Adaptation to Climate Variability and Change, 75-102. Springer.

[20] Klima, Grzegorz, Karol Podemski, and Kaja Retkiewicz-Wijtiwiak. 2015. "GEcon: General Equilibrium Economic Modelling Language and Solution Framework." R Package Version 0.8 3.

[21] Kubiszewski, Ida, Robert Costanza, Carol Franco, Philip Lawn, John Talberth, Tim Jackson, and Camille Aylmer. 2013. "Beyond GDP: Measuring and Achieving Global Genuine Progress." Ecological Economics 93: 57-68.

[22] Kwakkel, Jan H, and Erik Pruyt. 2013. “Exploratory Modeling and Analysis, an Approach for Model-
Based Foresight under Deep Uncertainty." Technological Forecasting and Social Change 80 (3): 419-31.

[23] Locatelli, Bruno, Vanessa Evans, Andrew Wardell, Angela Andrade, and Raffaele Vignola. 2011. "Forests and Climate Change in Latin America: Linking Adaptation and Mitigation." Forests 2 (1): 431-50.

[24] Locatelli, Bruno, Pablo Imbach, and Sven Wunder. 2014. "Synergies and Trade-Offs between Ecosystem Services in Costa Rica." Environmental Conservation 41 (1): 27-36.

[25] Locatelli, Bruno, Markku Kanninen, Maria Brockhaus, Carol Pierce Colfer, Daniel Murdiyarso, and Heru Santoso. 2008. "Facing an Uncertain Future: How Forests and People Can Adapt to Climate Change." CIFOR.

[26]Locatelli, Bruno,CharlottePavageau,EmiliaPramova, and Monica Di Gregorio. 2015. “Integrating Climate Change Mitigation and Adaptation in Agriculture and Forestry: Opportunities and Trade-offs." Wiley Interdisciplinary Reviews: Climate Change 6 (6): 585-98.

[27] Pramova, Emilia, Bruno Locatelli, Houria Djoudi, and Olufunso A Somorin. 2012. "Forests and Trees for Social Adaptation to Climate Variability and Change." Wiley Interdisciplinary Reviews: Climate Change 3 (6): 581-96.

[28] Ramírez, Martín López. 2016. “When Does the Integration of Mitigation and Adaptation in the Land Use Sector Actually Makes Sense?" Ekonomia. Rynek, Gospodarka, Społeczeństwo, no. 46: 101-19.

[29] Reed, James, Josh van Vianen, Samson Foli, Jessica Clendenning, Kevin Yang, Margaret MacDonald, Gillian Petrokofsky, Christine Padoch, and Terry Sunderland. 2017. "Trees for Life: The Ecosystem Service Contribution of Trees to Food Production and Livelihoods in the Tropics." Forest Policy and Economics 84: 62-71.

[30] Specht, Maria Joana, Severino Rodrigo Ribeiro Pinto, Ulysses Paulino Albuquerque, Marcelo Tabarelli, and Felipe P L Melo. 2015. “Burning Biodiversity: Fuelwood Harvesting Causes Forest Degradation in Human-Dominated Tropical Landscapes." Global Ecology and Conservation 3: 200-209. 
[31] R Core Team. 2013. "R: A Language and Environment for Statistical Computing." Vienna, Austria, R Foundation for Statistical Computing https://www.R-project.org/

[32] Wickham, Hadley. 2016. Ggplot2: Elegant Graphics for Data Analysis. Springer.

[33] Wickham, Hadley, Romain Francois, Lionel Henry, and Kirill Müller. 2015. “Dplyr: A Grammar of Data Manipulation. R Package Version 0.4. 3." R Found. Stat. Comput., Vienna. Https://CRAN. R-Project. Org $/$ Package $=$ Dplyr. 


\section{Appendix}

\section{A.1. Equilibrium determination}

As it was mentioned before, the model described in section 2.3 was implemented in the $R$ package $g$ Econ to derive numerical solutions. Specifically, the maximization problem of each subsector (see equation (1)) was used to derive first order conditions, which along with identities (equations (3)-(5)) and equilibrium conditions (zero profit and market clearing of factors), defined a system of simultaneous equations.

For this application, the system mentioned consisted of fifteen equations: eight of them were derived from optimization problems of each subsector (profit, production and marginal product of factors). The identities (equations that hold at any state) are the provision of ecosystem services and provided another three equations (C, H and E, see equations (3)-(5)). Equilibrium conditions defined the remaining four equations.

The numerical equilibrium solution of the problem, thus, consisted of fifteen variables: the characterization each subsector (profit, output, factor allocation and shadow prices), prices of factors and provision level of ecosystem services (see Table 3). The relevant quantities were used to calculate GDP (equation (2)) and perform the rest of the analysis described before. Notice that fixed and random parameters specifications can be found in Table 1.

The files required and instructions to reproduce the results are available under request to the author.

\section{A.2. Regulating Measures}

As it was shown in equation (1), regulating measures took the form of Pigouvian taxes or subsidies on land use. Based on sector and ES considered, the Pigouvian corrective measure was calculated using the appropriate form of equation (5), this is treating one of the arguments of the function as constant. For example, if the externality caused by deforestation is internalized, the agriculture sector is taxed on land used based on the mentioned equation treating the variable $H$ as constant. Alternatively, if the externality caused by degradation on hydrological services is internalized, a Pigouvian corrective measure is calculated based on equation (5) treating carbon as a constant. When the economy is left unregulated, the Pigouvian measure is simply set to zero $(t=0)$.

One important consequence of the process described above is that internalizing $C$ (e.g. in the case of a mitigation policy), leads to a tax on the subsector in which policy is considered $(t>0)$. This is because the sign of the expression is determined by the derivative of the environment with respect to land, assumed to be negative in the case mentioned. On the contrary, when hydrological services are internalized, the result is a subsidy $(t<0)$. A reasoning analogous to the previous case applies. It must be considered that when both ES are considered (configuration not explored in this paper), the sign of the derivative is determined by the specific set of parameters.

\section{A.3. Forest Transition}

Forest transition refers to the process that forest cover exhibits over timeas a country develops ineconomic terms (Barbier, Burgess, and Grainger 2010). The mentioned process takes place in a four phases: pre-transition, early transition, late transition and post transition (Hosonuma et al. 2012). The main characteristic of the pre-transition phase is a high and stable forest cover. During the early transition, deforestation rate increases and forest cover declines. At late transition, forest cover stabilizes in a relatively low level. During post-transition phase, a reforestation process drives forest cover recovery. The end result is a " $U$ " shape pattern of forest cover over time (Barbier, Burgess, and Grainger 2010; Lambin and Meyfroidt 2010).

Using the mentioned framework, Hosonuma et al. (2012) classified 100 tropical and subtropical countries (non-annex I of UNFCCC) in one of the four phases of the forest transition process. A full list of countries is provided in the appendix of the article mentioned.

Table 4 shows the average forest cover in relative terms per phase of the forest transition. The calculations are based on forest cover reported in 2010 (last year used for classification in the original study) for the World Bank (2018). The information showed in Table 4 was used to calibrate the model as specified in section 2.4.1. 